\title{
Study of lymphnode lesions by fine needle aspiration cytology and histopathology: A study of 125 cases
}

\author{
Patel D. ${ }^{1}$, Patel R. ${ }^{2}$ \\ ${ }^{1}$ Dr. Dipeeka Patel, Consultant Pathologist, Department of Pathology, MGG Hospital Navsari, ${ }^{2}$ Dr. Ragini Patel, Tutor, \\ Department of Pathology, GMERS Medical College, Valsad, Gujarat, India.
}

Corresponding Author: Dr. Ragini Patel, Tutor, Department of Pathology, GMERS Medical College, Valsad, Gujarat, India. E-mail: rags3276@gmail.com

\begin{abstract}
Background: Fine needle aspiration cytology (FNAC) is a simple and rapid diagnostic technique and because of early availability of results, simplicity, minimal trauma and complication, the aspiration cytology is now considered as a valuable diagnostic aid and is gaining popularity. It also helps in giving proper direction for appropriate investigations. Objectives: To find out number of cases where FNAC of the lymph nodes picked up an unsuspected malignancy and to correlate the cytological findings with the histopathological findings in cases where lymph node biopsy is done. Methodology: It was a prospective study done on patient who presented with lymphadenopathy to various departments and referred to pathology department. The aspirate was collected from the enlarged lymphnodes using standard procedure with proper aseptic condition. The aspirate was examined for the amount and nature of the aspirated material, and then several smears were prepared. Smears were immediately fixed in 95\% ethyl alcohol, and these smears were examined using various stains like haematoxylin and eosin stain, PAS stain also MGG's stain and Ziehl Neelsen stain. Observations: out of total 125 patients, $91(73.60 \%)$ were Male patients and $34(26.40 \%)$ were Female patients with M:F ratio of 2.79:1 with Male predominance. Distributions of all lymph node lesions shows cervical site i.e. 97 (77.6\%) followed by inguinal i.e. $14(11.2 \%)$ and other sites. Among all lymphnode lesions, 66.40\% were neoplastic lesions and $33.60 \%$ were non- neoplastic lesions. Neoplastic lesions were more common in cervical group and Metastatic squamous cell carcinoma was more common in cervical group. Cytological diagnosis was correlated with histopathology diagnosis in $13.6 \%$ cases. Conclusion: FNAC can help not only to differentiate among lymphoma, and metastasis, but also to identify nonspecific reactive lymphadenitis and specific infections such as tuberculosis lymphadenitis. The results are quite encouraging and even more advanced diagnostic tools available, FNAC can still recommended as the initial diagnostic test in the evaluation of superficial lymphadenopathy.
\end{abstract}

Keywords: FNAC, Superficial lymphadenopathy, Histopthological diagnosis.

\section{Introduction}

The lymph node is one of the major anatomic components of the immune system. Lymph nodes are the most widely distributed and easily accessible component of lymphoid tissue and hence they are frequently examined for diagnosis of lymphoreticular disorders [1,2]. They are the site of clonal expansion and differentiation of lymphocytes necessary for an effective adaptive immune response [1,2].

A normal lymph node is rarely palpable. Cytological characteristics of cells from a normal lymph node are essentially based on the morphology of individual cells as observed in the aspirate from a reactive lymph node.

Manuscript received: $4^{\text {th }}$ May 2019

Reviewed: $14^{\text {th }}$ May 2019

Author Corrected: $20^{\text {th }}$ May 2019
Accepted for Publication: $23^{\text {rd }}$ May 2019

The lymphocytes constitute $87 \%$ to $99 \%$, Plasma cells $0 \%$ to $5 \%$ and remainder cells $1 \%$ to $3 \%$ (histiocytes, mast cells, eosinophils and neutrophils) [3]. Diagnosis of lymphadenopathy depends mainly on excision of a gland and histopathological examination. For this, general anaesthesia and hospitalization are required.

Fine needle aspiration cytology, on the other hand, is free from these disadvantages and can safely be used as an alternative or complementary investigative technique [1]. Fine needle aspiration cytology (FNAC) is a simple and rapid diagnostic technique. Because of early availability of results, simplicity, minimal trauma and complication, the aspiration cytology is now considered as a valuable diagnostic aid and is gaining popularity 
[4]. The cytomorphological features obtained in needle aspiration, frequently correlate very well with histologic appearance of the same lesion and in some situations has qualities of a micro-biopsy. The FNAC, along with making a diagnosis, it also helps in giving proper direction for appropriate investigations. Aspirates from lymph nodes are usually very cellular and their interpretation varies from clear diagnosis to a firm request for histopathology.

The objective of the study was to find out number of cases where FNAC of the lymph nodes picked up an unsuspected malignancy (primary or secondary). And to correlate the cytological findings with the histopathological findings in cases where lymph node biopsy is done.

\section{Materials and Methodology}

Type of the study and study setting: It was a prospective study done on patient who presented with lymphadenopathy and referred to the Department of pathology Medical College Baroda, S.S.G. Hospital, Baroda for fine needle aspiration cytology and those underwent subsequent biopsy.

Ethical consideration: Human Research Ethics Committee permission was taken before starting of the study.

Inclusion Criteria: Patients with superficial as well as deep lymphadenopathies mainly referred by ENT, TB $\&$ Chest, Surgery, Paediatric, and Medicine departments of S.S.G. Hospital, Medical Collage Baroda.

Exclusion Criteria: Acellular fine needle aspirations were excluded from this study.

Methods of collection of data: All the referred patients were clinically examined and the procedure of aspiration biopsy was explained to the patient including reliability, limitations and complications. Patients were included in the study only after proper informed consent.

Aseptic precautions were taken and aspiration of the selected lymph node was done. After, the overlying skin was stretched, the lymph node was grasped between the index finger and the thumb of the left hand; a sterile 22 or 23 gauge needle fitted to a $10 \mathrm{ml}$ syringe was pierced

\section{Original Research Article}

obliquely into the lymph node. The plunger was then withdrawn and the negative pressure was created in the syringe, after entering the lymph node mass. The needle was moved back and forth several times with a constant suction.

The negative pressure was released and the needle was removed from the mass. The needle containing the aspirated material was then detached and air was drawn into the syringe. After reattachment of the needle, content of the needle was ejected out on the clean, dry and grease free glass slides.

Smears were prepared using another glass slide exerting light pressure. The aspirate was examined for the amount and nature of the aspirated material, and then several smears were prepared. Smears were immediately fixed in $95 \%$ ethyl alcohol, and these smears were stained by haematoxylin and eosin stain, PAS stain. Air dried smears were also prepared and stained with MGG's stain.

Ziehl Neelsen stain was done for all the cases where necrotic material was aspirated or clinically suspected tuberculosis and HIV. Smears were examined and cytological diagnosis offered. Data regarding relevant radiological, biochemical and haematological investigations done for diagnostic purposes were collected.

Lymph nodes of the patients who underwent subsequent surgical biopsy were fixed in $10 \%$ formalin and subjected to gross examination. Biopsy specimens were routinely processed to obtain $3-6 \mu \mathrm{m}$ paraffin sections, which were stained with haematoxylin and eosin stains.

Special stains like Ziehl Neelsen stain, PAS were done when ever indicated.

For immunohistochemistry $4-5 \mu$ sized sections of the formalin fixed paraffin embedded tissue was used. The sections were stained using the standard technique of immunohistochemistry. Study was done separately and then results of cytological and histopathological study were correlated to evaluate efficacy of the procedure.

Statistical Analysis: A simple descriptive data analysis method was done using Microsoft Excel.

\section{Results}

The present study deals with fine needle aspiration cytology of lymph nodes taken by cytology section and out of these cases, biopsy or excised lymph nodes taken by surgeon and sent to Histopathology section of pathology department. 


\section{Original Research Article}

According to inclusion and exclusion criteria fine needle aspirations of 125 patients were considered for FNAC in the study and out of these 17 (13.6\%) biopsies were evaluated for histopathology study.

In the current study gender wise distribution shows that, out of total 125 patients, 91 (73.60\%) were Male patients and 34 $(26.40 \%)$ were Female patients. Male to Female ratio was (2.79:1) with Male predominance. Age of patients was ranging from 0 to 80 years. Peak incidence of lymph node lesion was seen in the age group of 41 to 50 years (33 cases, 26.4\%), followed by 51 to 60 years (29 Cases, 23.2\%) and 61 to 70 (24 Cases, 19.2\%) years. [Table 1]

Table-1: Age and Gender wise distribution of all cases of lymph node lesions $(n=125)$.

\begin{tabular}{|c|c|c|c|}
\hline \multirow{2}{*}{ Age } & \multicolumn{2}{|c|}{ Gender } & \multirow{2}{*}{ No. of patients (\%) } \\
\cline { 2 - 3 } & Male & Female & \\
\hline $0-10$ & 2 & 2 & $4(3.2)$ \\
\hline $11-20$ & 4 & 2 & $6(4.8)$ \\
\hline $21-30$ & 7 & 3 & $10(8.0)$ \\
\hline $31-40$ & 7 & 4 & $11(8.8)$ \\
\hline $41-50$ & 23 & 10 & $33(26.4)$ \\
\hline $51-60$ & 23 & 6 & $29(23.2)$ \\
\hline $61-70$ & 20 & 4 & $8(19.2)$ \\
\hline $71-80$ & 5 & 3 & $0(0.0)$ \\
\hline $81-90$ & 0 & 0 & $\mathbf{1 2 5}(\mathbf{1 0 0 . 0})$ \\
\hline Total & $\mathbf{9 1}(\mathbf{7 3 . 6 0} \%)$ & $\mathbf{3 4} \mathbf{( 2 6 . 4 0 \% )}$ & \\
\hline
\end{tabular}

Anatomical distributions of all lymph node lesions shows highest numbers of sample were received from cervical site i.e. 97 (77.6\%) followed by inguinal i.e. 14 (11.2\%). However, 2 patients had generalized lymph node lesions. [Figure 1]

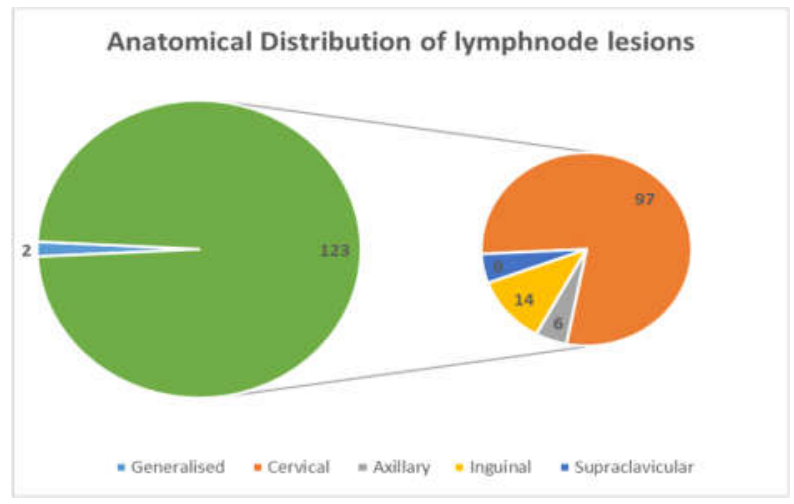

Figure-1: Anatomical distribution of all lymph node lesions $(n=125)$

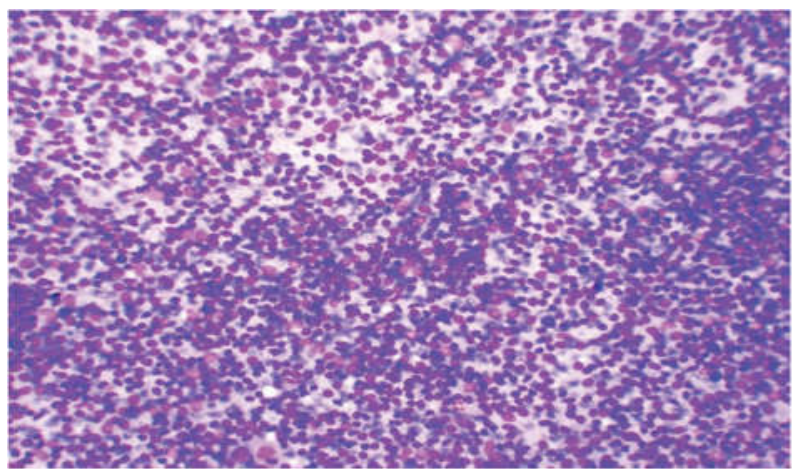




\section{Original Research Article}

Figure-2: Smears shows polymorphous population of lymphoid cells in Reactive lymphadenitis (MGG stain $x$ 400)

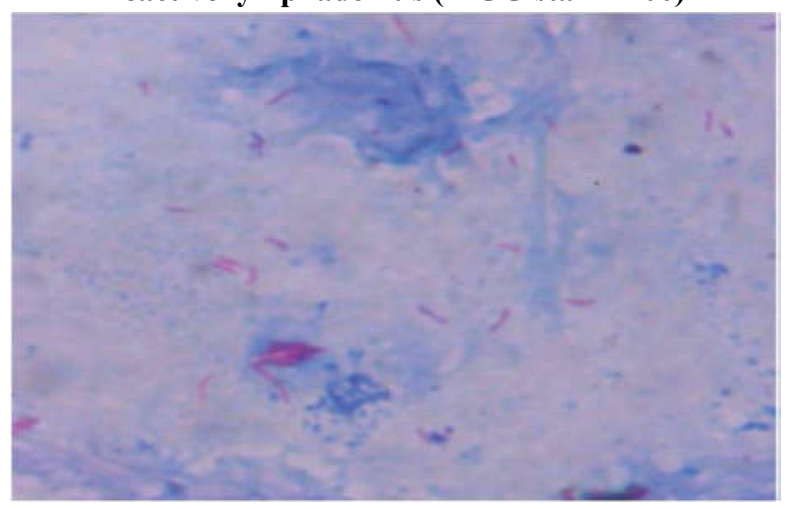

Figure-3: Acid fast bacilli in tuberculosis lymphadenitis (ZN stain)(oil immersion)

Out of all lymph node lesions neoplastic lesions were (83 cases, 66.40\%) and Non neoplastic lesions were (42 cases, $33.60 \%$ ). In non- neoplastic lesions Reactive lymphadenitis was most common (27 cases, 21.6\%). [Figure 2] In the present study reactive lymphadenitis was most common in 11-20 years of age group (7cases; $25.92 \%$ ) followed by 51-60 years of age ( 6 cases; $22.22 \%$ ). Male to Female ratio for reactive lymphadenitis was 2:1 with male predominance. While tuberculosis lymphadenitis was most common in 21-30 years of age group ( 6 cases, $40 \%$ ) followed by 31-40 years of age group (3cases, 20\%). [Figure 3] Male to Female ratio was 1:1.5 with Female predominance. Among neoplastic lesions metastatic lesions were most common (79 cases, 63.2\%) and only 4 cases had lymphoma. Lymphoma cases were seen only in Male patients. 1 case of Hodgkin lymphoma was seen in 0-10 year of age group, while rest of 3 cases of Non Hodgkin lymphoma were seen in 31-40 years of age group, 41-50 years of age group and 61-70 years of age group. [Table 2]

Table-2: Cytological diagnosis of lymphnode lesions $(n=125)$.

\begin{tabular}{|c|c|c|}
\hline Lymph node lesions & Number of cases & Percentage \\
\hline \multicolumn{3}{|c|}{ Non-neoplastic lesions } \\
\hline Reactive lymphadenitis & 27 & $21.6 \%$ \\
\hline Tuberculosis lymphadenitis & 15 & $12.0 \%$ \\
\hline \multicolumn{3}{|c|}{ Neoplastic lesions } \\
\hline Metastatic Lesions & 79 & $63.2 \%$ \\
\hline NHL & 3 & $2.4 \%$ \\
\hline HL & 1 & $0.8 \%$ \\
\hline Total & $\mathbf{1 2 5}$ & $\mathbf{1 0 0 \%}$ \\
\hline
\end{tabular}

Neoplastic lesions were more common in cervical group (79 cases, 84.33\%) followed by supraclavicular (5 cases, $6.02 \%$ ). Metastatic squamous cell carcinoma was more common in cervical group (40 cases, 57.14\%) followed by metastatic epithelial malignancy (15 cases, 21.34\%).[Table 3] [Figure 4 \& 5]

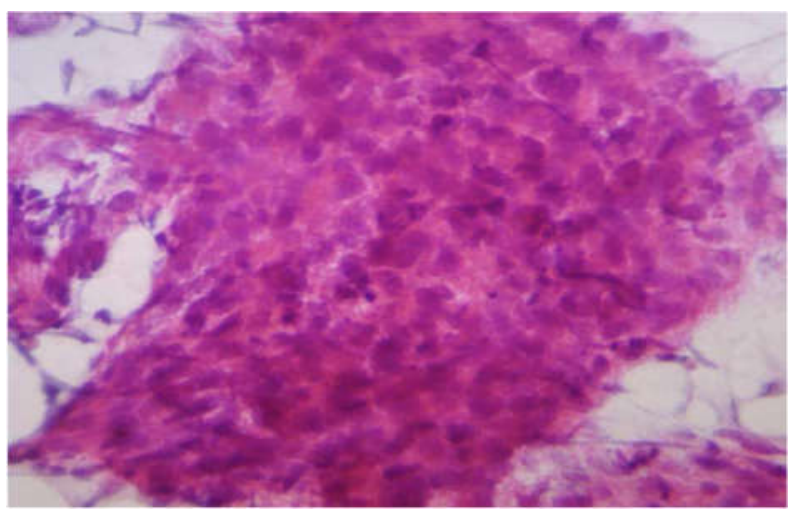




\section{Original Research Article}

Figure-4: Metastatic squamous cell carcinoma of lymph node (H\& E x400)

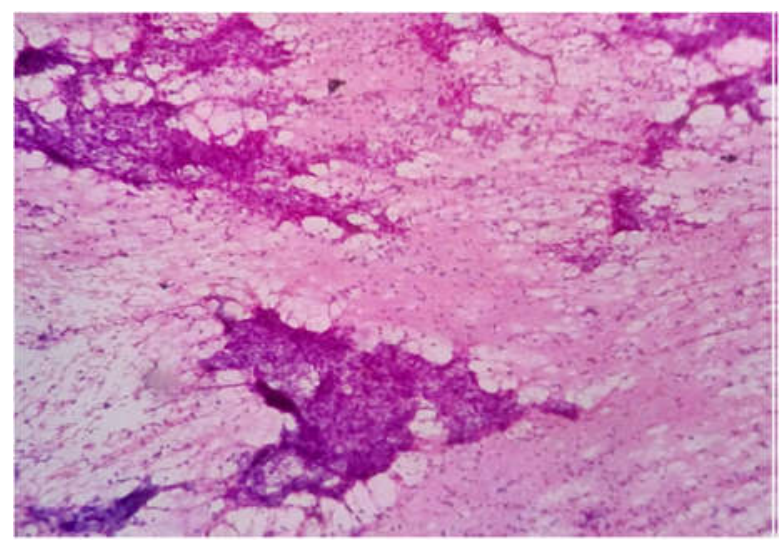

Figure-5: Metastatic Epithelial Malignancy of lymph node. (H\&E X 100)

Table-3: Distribution according to site and type of neoplastic lesions of lymph node. $(\mathrm{N}=83$ )

\begin{tabular}{|c|c|c|c|c|c|}
\hline Cytological diagnosis & Cervical & Supraclavicular & Axillary & Inguinal & Total \\
\hline \multicolumn{6}{|l|}{ Metastatic lesions } \\
\hline Metastatic SCC & 40 & 2 & 0 & 2 & 44 \\
\hline $\begin{array}{l}\text { Metastatic } \\
\text { adenocarcinoma }\end{array}$ & 5 & 0 & 0 & 0 & 5 \\
\hline $\begin{array}{l}\text { Metastatic epithelial } \\
\text { malignancy }\end{array}$ & 15 & 2 & 1 & 1 & 19 \\
\hline Malignant melanoma & 0 & 0 & 0 & 1 & 1 \\
\hline Undifferentiated tumour & 7 & 1 & 2 & 0 & 10 \\
\hline \multicolumn{6}{|l|}{ Primary tumour } \\
\hline NHL & 2 & 0 & 1 & 0 & 3 \\
\hline HL & 1 & 0 & 0 & 0 & 1 \\
\hline Total & $70(84.33 \%)$ & $5(6.03 \%)$ & $4(4.81 \%)$ & $4(4.81 \%)$ & $83(100 \%)$ \\
\hline
\end{tabular}

Table-4: Clinico-cytological correlation of all neoplastic lesions $(n=83)$.

\begin{tabular}{|c|c|c|c|}
\hline & $\begin{array}{c}\text { Clinically suspected } \\
\text { cases }\end{array}$ & $\begin{array}{c}\text { Clinically unsuspected } \\
\text { cases }\end{array}$ & Cytological diagnosis \\
\hline \multicolumn{4}{|l|}{ Metastatic lesion } \\
\hline $\begin{array}{l}\text { Metastatic squamous cell } \\
\text { carcinoma }\end{array}$ & 26 & 18 & 44 \\
\hline Metastatic adenocarcinoma & 3 & 2 & 5 \\
\hline $\begin{array}{l}\text { Metastatic epithelial } \\
\text { malignancy }\end{array}$ & 10 & 9 & 19 \\
\hline Malignant melanoma & 0 & 1 & 1 \\
\hline Undifferentiated tumour & 5 & 5 & 10 \\
\hline Total & $44(55.70 \%)$ & $35(44.30 \%)$ & 79 \\
\hline \multicolumn{4}{|l|}{ Primary tumours } \\
\hline NHL & 1 & 2 & 3 \\
\hline HL & 0 & 1 & 1 \\
\hline
\end{tabular}




\section{Original Research Article}

\begin{tabular}{|l|c|c|c|}
\hline Total & $1(25 \%)$ & $3(75 \%)$ & 4 \\
\hline
\end{tabular}

Table-5: Correlation with cytology diagnosis with histopathological findings.

\begin{tabular}{|c|c|c|c|c|}
\hline Cytological Diagnosis & $\begin{array}{l}\text { No of } \\
\text { cases }\end{array}$ & $\begin{array}{c}\text { HP } \\
\text { correlated }\end{array}$ & HP not correlated & $\begin{array}{c}\% \text { of accuracy of } \\
\text { cytology and } \\
\text { histopathology }\end{array}$ \\
\hline Reactive lymphadenitis & 10 & 6 & $\begin{array}{c}2 \text { Tuberculosis lymphadenitis } \\
1 \mathrm{HL} \\
1 \mathrm{NHL}\end{array}$ & $60 \%$ \\
\hline Tuberculous lymphadenitis & 3 & 2 & $1 \mathrm{HL}$ mixed cellularity & $66.67 \%$ \\
\hline Metastatic carcinoma & 4 & 3 & 1 No malignancy & $75 \%$ \\
\hline
\end{tabular}

Table-6: Diagnostic reliability of cytopathological diagnosis of lymphnode as compared with histopathological diagnosis in patients with lymphadenopathy.

\begin{tabular}{|c|c|c|}
\hline Statistical Parameter & Percentage & 95\%CI (\%) \\
\hline Sensitivity & $76.92 \%$ & $46.19 \%$ to $94.96 \%$ \\
\hline Specificity & $75.00 \%$ & $19.41 \%$ to $99.37 \%$ \\
\hline PPV & $90.91 \%$ & $64.09 \%$ to $98.25 \%$ \\
\hline NPV & $50.00 \%$ & $24.19 \%$ to $75.81 \%$ \\
\hline Accuracy & $76.47 \%$ & $50.10 \%$ to $93.19 \%$ \\
\hline
\end{tabular}

Out of 79 cases of cytological diagnosed metastatic lesions, 44 cases (55.69\%) clinically suspected and 35 cases $(44.30 \%)$ were clinically unsuspected cases of metastatic lesions. And Out of 4 cases cytological diagnosed of lymphoma, 1 case (25\%) was clinically suspected and 3 cases (75\%) were clinically unsuspected. [Table 4]

Cytological diagnosis was correlated with histopathology diagnosis in 17(13.6\%) cases. Cytology diagnosis of 10 cases of reactive lymphadenitis correlated with histopathology diagnosis in 6 cases and accuracy rate was 60\%. Cytology diagnosis of 3 cases of tuberculosis lymphadenitis correlated with 2 cases and accuracy rate was 66.67\%. Cytology diagnosis of 4 cases of metastatic lesions correlated with histopathology diagnosis in 3 cases and accuracy was $75 \%$. [Table 5]

Overall sensitivity of FNAC was $76.92 \%$, specificity was $75.00 \%$, positive predictive value was $90.91 \%$ and Negative predictive value was $50.00 \%$ and Accuracy was $76.47 \%$. [Table 6]

\section{Discussion}

Lymphadenopathy as a clinical manifestation of the regional or systemic disease serves as an excellent clue to the underlying disease. It can arise either from benign or malignant causes depending on the geographical condition and socioeconomic setup [5]. FNAC is a simple, safe, reliable, rapid, and inexpensive method of establishing the diagnosis of lesions and masses in various sites and organs. In the present study, a total 125 cases of FNAC of lymph nodes taken in cytology section and out of 17 (13.6\%) cases of biopsy or excised lymph node taken by surgeon and sent to histopathology section Medical College Baroda during study period from November 2016 to October 2017.
Demographical distributions of the study show male were $73.60 \%$ and female were 26.40 . These results were near comparable with Shruti Vimal et al [6] study in

which male were $54.55 \%$ and female were $45.46 \%$ and in study by Hirachand et al [5] in which male were $52.31 \%$ and female were $47.69 \%$. Age wise distribution also similar to other studies like Hirachand et al [5] and Nesreen et al [6] with youngest patient in both study 3 and 4.5 years respectively and oldest patient was 85 and 80 years respectively that is nearly similar to the present study.

In present study, non -neoplastic lesions were $33.6 \%$ and neoplastic lesions were $66.4 \%$. These results were comparable with Nesreen et al [6] study in which nonneoplastic lesions were $30.6 \%$ and neoplastic lesions 
were $69.4 \%$ and with Steel et al [8] study in which non neoplastic lesions were $34 \%$ and neoplastic lesions were $59 \%$. In the present study most common site for lymph node lesions was cervical region $77.6 \%$. These results were near comparable with Dr. Ripunjaya et al [9] in which $66.48 \%$ and Hirachand et al [5] in which $50.76 \%$. In the present study reactive lymphadenitis was $21.6 \%$. These results were near comparable with Khajura et al [10] in which reactive lymphadenitis was $37.1 \%$. metastatic lesions of lymph node were $95.18 \%$. These results were comparable with Alam et al [11] in which $90 \%$ and with Dr. Ripunjaya et al [9] study in which $82 \%$. In the present study Male: Female ratio for metastatic lymph node lesions were 3.9:1.

These results were comparable with Mehrotra et al [12] in which Male: Female ratio was 3.8:1 and with Naresh et al [13] in which Male: Female ratio was 3.8:1. Cervical region was most common site for metastatic lesions were $84.81 \%$. These results were near comparable with Pratibha et al [14] in which $75.2 \%$. lymphoma cases were $3.2 \%$. These results were comparable with Shruti Vimal et al [15] in which lymphoma were cases $2.67 \%$.

In present study, clinically suspected malignant cases were $55.69 \%$ and clinically unsuspected cases were $44.30 \%$. Similar results found by Ripunjaya et al [9] in which clinically suspected cases were $66.15 \%$ and clinically unsuspected cases were $18.46 \% .75 \%$ primary malignant cases were clinically unsuspected and $25 \%$ cases were clinically suspected. While in Ripunjaya et al [9] study $42.88 \%$ cases were clinically unsuspected and $57 \%$ cases were clinically suspected. This deviation could be because of in present study clinically unsuspected cases were $75 \%$ ( 3 cases), 1 case was child in which reactive lymphadenitis is more common and other 2 cases had past history suggestive of tuberculosis and HIV positive. So, clinician may not have suspect primary malignant lesions.

The accuracy rate for metastatic lesions was $75 \%$ near comparable with Ripunjaya et al [9] study in which accuracy rate for metastatic lesion was $100 \%$. One case of metastatic lesion was not correlated with histopathology diagnosis in present study. It may be due to biopsy was taken very superficial from lesions. The accuracy rate for reactive lymphadenitis was $60 \%$ and in Ripunjaya et al study, accuracy rate for reactive lymphadenitis was $100 \%$.

It may be due to in present study all non-tuberculosis cases were included in reactive lymphadenitis, while in Ripunjaya et al study, acute lymphadenitis cases in which accuracy rate was $(57 \%)$ were taken separately

\section{Original Research Article}

from reactive lymphadenitis. In the present study (Tuberculosis, 3 Cases) accuracy rate for tuberculosis lymphadenitis was $66.67 \%$ (2 Cases), while in Ripunjaya et al study, in which accuracy rate for tuberculosis was $100 \%$. In the present study third case of cytological diagnosed tuberculosis was also advised for excision biopsy for confirmation, as few atypical cells were suspicious, which was diagnosed malignant lymphoma in biopsy.

In the present study specificity and accuracy were $75 \%$ and $76.41 \%$ comparable with Nesreen et al in which specificity of was $67.2 \%$ and Accuracy was $82.2 \%$. In the present study sensitivity was $76.92 \%$ near comparable with Nesreen et al study in which $90.9 \%$ [6].

\section{Conclusion}

The recent trend in medical practice is toward adopting a diagnostic modality, which is both cost effective and minimally invasive. In this regard, FNAC is often used as a first line of investigation for screening cases with lymphadenopathy, since this method is easy to perform, rapid, and inexpensive. FNAC can help not only to differentiate among lymphoma, and metastasis, but also to identify nonspecific reactive lymphadenitis and specific infections such as tuberculosis lymphadenitis.

The results are quite encouraging and FNAC can be recommended as the initial diagnostic test in the evaluation of superficial lymphadenopathy. Although FNAC has proven to be a simple, safe, reliable and cost effective diagnostic tool for lymphadenopathies, the limitation of the procedure should be kept in mind and excision biopsy should be used whenever required. Immunohistochemistry staining is useful for confirmation of diagnosis in nodal lesions especially lymphoma and for further classification of lymphomas.

All authors had contributed equally in study design, conduct of study, data analysis and manuscript making.

Findings: Nil; Conflict of Interest: None initiated Permission from IRB: Yes

\section{References}

1. Loachim HL, Medeiros LJ. Ioachim's lymph node pathology, ed. 4. Lippincott Williams \& Wilkins. Philadelphia, 2008.

2. Delves PJ, Roitt IM. The immune system. First of two parts. N Engl J Med. 2000 Jul 6;343(1):37-49.DOI: 10. 1056/NEJM200007063430107 
3. Stein $\mathrm{H}$, Bonk A, Tolksdorf $\mathrm{G}$, et al. Immunohistologic analysis of the organization of normal lymphoid tissue and non-Hodgkin's lymphomas. J Histochem Cytochem. 1980 Aug;28(8):746-60.

4. Prasad RR, Narasimhan R, Sankaran V, et al. Fineneedle aspiration cytology in the diagnosis of superficial lymphadenopathy: an analysis of 2,418 cases. Diagn Cytopathol. 1996 Dec;15(5):382-6.

5. Hirachand S, Lakhey M, Akhter J, et Evaluation of fine needle aspiration cytology of lymph nodes in Kathmandu Medical College, Teaching hospital. Kathmandu Univ Med J (KUMJ). 2009 Apr-Jun;7 (26): 139-42.

6. Vimal S, Dharwadkar A, Chandanwale SS, Vishwanathan V, Kumar H. Cytomorphological study of lymph node lesions: A study of 187 cases. Med J DY Patil Univ 2016;9:43-50.

7. Hafez NH, Tahoun NS. Reliability of fine needle aspiration cytology (FNAC) as a diagnostic tool in cases of cervical lymphadenopathy. J Egypt Natl Canc Inst. 2011 Sep;23(3):105-14. doi: 10.1016/j.jnci.2011. 09.009. Epub 2011 Oct 24.

8. Steel BL, Schwartz MR, Ramzy I. Fine needle aspiration biopsy in the diagnosis of lymphadenopathy in 1,103 patients. Role, limitations and analysis of diagnostic pitfalls.Acta Cytol. 1995Jan-Feb;39(1):76-81

\section{Original Research Article}

9. Mohanty R, Wilkinson A. Utility of fine needle aspiration cytology of lymph nodes. IOSR Journal of Dental and Medical Sciences. 2013;8:13-8.

10. Khajuria R, Goswami KC, Singh K, Dubey VK. Pattern of lymphadenopathy on fine needle aspiration cytology in Jammu. JK Sci. 2006;8:145-9.

11. Alam K, Khan A, Siddiqui F, Jain A, Haider N, Maheshwari V. Fine needle aspiration cytology (FNAC), a handy tool for metastatic lymphadenopathy. Int J Pathol. 2010;10(2).

12. Mehrotra R, Singh M, Gupta RK, et al. Trends of prevalence and pathological spectrum of head and neck cancers in North India. Indian J Cancer. 2005 Apr-Jun; 42 (2):89-93.

13. Rai NN, Patangia P, Meena SP. Role of fine needle aspiration cytology in diagnosis of metastatic lymphadenopathy. J. Evid. Based Med. Healthc. 2016; 3: 738-41.

14. Meena P, Mishra RT. A study of metastatic lesions of lymph nodes by fine needle aspiration cytology. Int $\mathrm{J}$ Res Med Sci 2017;5:4523-6.

15. Vimal S, Dharwadkar A, Chandanwale SS, Vishwanathan V, Kumar H. Cytomorphological study of lymph node lesions: A study of 187 cases. Med J DY Patil Univ 2016;9:43-50.

\section{How to cite this article?}

Patel D, Patel R. Study of lymphnode lesions by fine needle aspiration cytology and histopathology: A study of 125 cases. Trop J Path Micro 2019;5(5):317-324.doi: 10.17511/jopm.2019.i05.10. 